\title{
Levobupivacaine and its Venodilatation Effect in the Upper Extremity After Axillary Brachial Plexus Block by Ultrasound Guidance
}

\author{
N. Aypa, J.M. Rayos del Sol \\ Makati Medical Center, Department of Anaesthesiology, Makati City, Philippines
}

\section{Background and Aims:}

Axillary Brachial Plexus Block (ABPB) causes vasodilatation and an increase in blood flow to the upper limb secondary to its sympathectomy effect. However, limited reports have evaluated the regional hemodynamic changes after Levobupivacaine $0.5 \%$ is used. Objective: To determine induced smooth muscle relaxation of cephalic vein with levobupivacaine $0.5 \%$ after ultrasoundguided axillary brachial plexus block for patients undergoing surgery of the upper limb. This study will focus on venodilatation that may help microsurgical operations requiring improved perfusion of the extremity, for endovascular / trauma surgeries

\section{Methods:}

A total of 43 patients were included in the study to determine induced smooth muscle relaxation of cephalic vein with levobupivacaine $0.5 \%$ after ultrasound-guided axillary brachial plexus block (ABPB) for patients undergoing surgery of the upper limb.
Mean cross-sectional area of cephalic vein in its native state (t0), immediately after the block (t1), and 20 minutes after the axillary brachial plexus block (t2) were compared for significant increase.

\section{Results:}

The study revealed that mean \% change in CSA from to to t1, from to to $t 2$, and from $t 1$ to $t 2$ was statistically significant from $0.0 \%$. This means that CSA of cephalic vein significantly increased immediately and 20 minutes after axillary brachial plexus block.

\section{Conclusion:}

There is a significant increase in cross-sectional diameter of the cephalic vein from native state to immediately and 20 minutes post-block. The increase in the degree of crosssectional diameter of the vein may contribute to the success of the microvascular procedures.

TABLE 1. Test of Significance: Cephalic Vein Measurement (at to, $t 1, t 2)$

\begin{tabular}{|lllll|}
\hline \multicolumn{1}{|c}{ Cephalic Vein Measurement } & \multicolumn{1}{c}{ to -} & $\begin{array}{c}\mathrm{t} 1- \\
\text { Native State } \\
\text { after the block }\end{array}$ & $\begin{array}{c}\text { t2 }- \\
\text { minutes after } \\
\text { the block }\end{array}$ & $\begin{array}{c}\text { p-value } \\
\text { (anova) }\end{array}$ \\
\hline Cephalic Vein Measurement & & & & \\
\hline Cranio-Caudal Diameter (cm) & $0.499 \pm 0.299$ & $0.602 \pm 0.340$ & $0.736 \pm 0.479$ & $0.017^{*}$ \\
\hline Antero-Posterior Diameter (cm) & $0.517 \pm 0.318$ & $0.673 \pm 0.386$ & $0.775 \pm 0.463$ & $0.011^{*}$ \\
\hline Cross-Sectional Area $\left(\mathbf{c m}^{2}\right)$ & $0.258 \pm 0.387$ & $0.389 \pm 0.529$ & $0.580 \pm 0.917$ & $0.073^{\text {ns }}$ \\
\hline
\end{tabular}

ns - not significant $\quad$ ** - significant at $5 \% \quad$ * - significant at $1 \%$

TABLE 2. Test of Significance: $\%$ Change in CSA ( $t 0-t 1$, to - $t 2, \& t 1-t 2)$

\begin{tabular}{|lcccc|}
\hline \% Change in CSA & CSA at Time1 & CSA at Time2 & \%Change in CSA & $\begin{array}{c}\text { p-value } \\
\text { (t-test) }\end{array}$ \\
\hline Covered Period & & & \\
\hline t0 - t1 & $0.258 \pm 0.387$ & $0.389 \pm 0.529$ & $67.60 \pm 54.12$ & $<0.001^{* *}$ \\
\hline t0 - t2 & $0.258 \pm 0.387$ & $0.580 \pm 0.917$ & $132.58 \pm 77.55$ & $<0.001^{* *}$ \\
\hline t1 - t2 & $0.389 \pm 0.529$ & $0.580 \pm 0.917$ & $42.79 \pm 44.21$ & $<0.001^{* *}$ \\
\hline ns - not significant & $* *$ - significant at $5 \%$ & $*$ - significant at $1 \%$ & &
\end{tabular}

